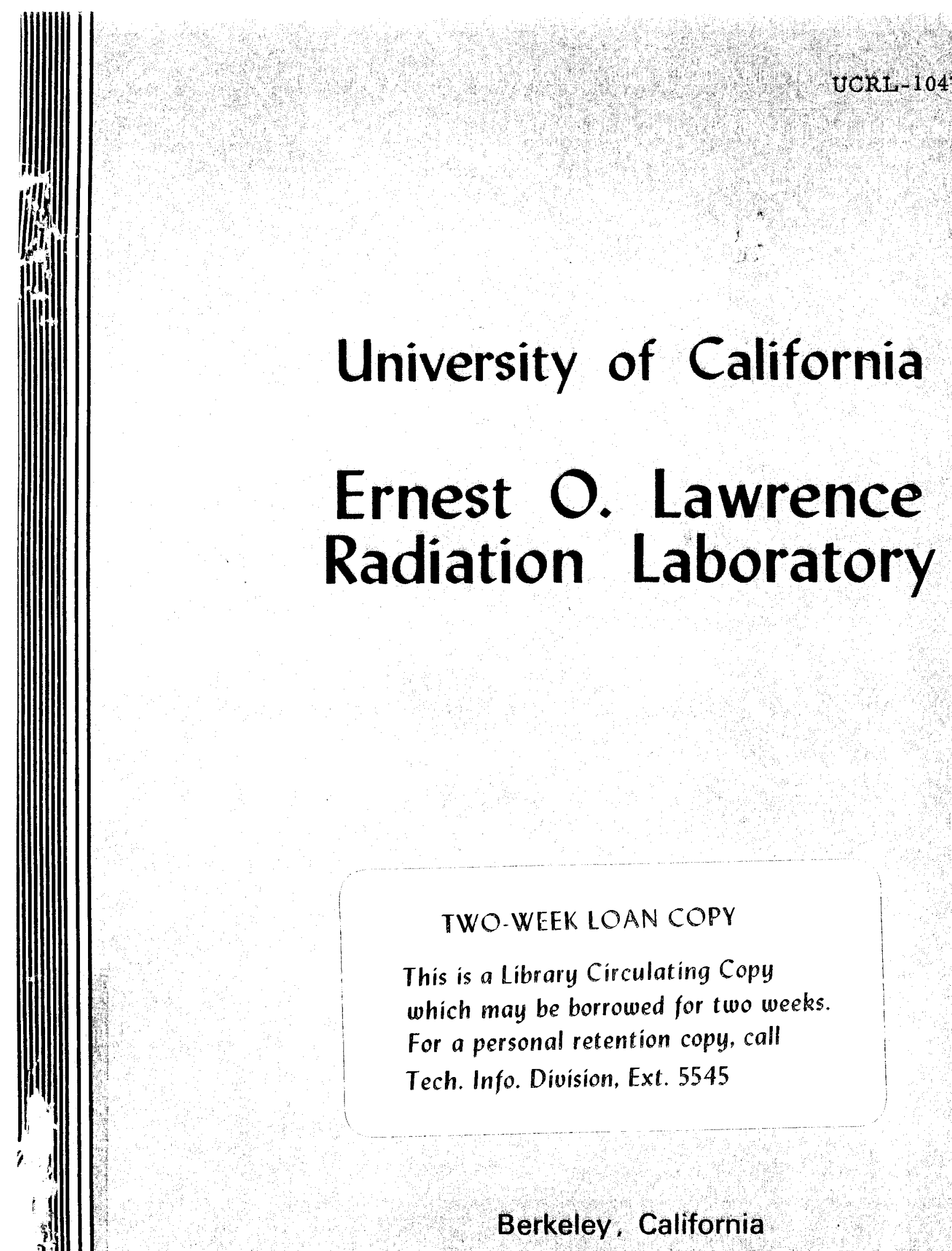




\section{UNIVERSITY OF CALIFORNIA \\ Lawrence Radiation Laboratory Berkeley, California}

Contract No. W-7405-eng-48

ADVENTURES IN NUCLEAR PHYSICS

Luis W. Alvarez

March 1962 


\title{
ADVENTURES IN NUCLEAR PHYSICS
}

\author{
By Luis W. Alvarez
}

The 1962 University of California

Faculty Research Lecture

March 1962

Chancellor Strong, and members of the University community:

I was a brand new instructor in the Physics Department, when I attended my first Faculty Research Lecture, which was given by Ernest Lawrence. Professor Lawrence had already been awarded many of the medals and honorary degrees which are now on display outside his old office on the hill. But as he said to me in private, and as he repeated on that occasion, he considered the Faculty Research Lectureship to be a particularly heartwarming honor to receive, because it represented the approval of his long-term scientific accomplishments, by those most qualified to give it-his own colleagues at a great institution of learning. I share Professor Lawrence's deep sense of gratitude at the honor you have conferred on me tonight, and I derive an additional sense of satisfaction from it, which he, as the first Berkeley physicist to be so honored couldn't have experienced. Since his time, three other colleagues of mine from the Physics Department have given this lecture. The fact that I have been judged worthy of having my name associated in this way with Ernest Lawrence, Raymond Birge, Edwin McMillan and Emilio Segrè, is to a physicist, a great honor all by itself, and I' $m$ grateful to those of you who were responsible for it.

A faculty research lecture is different from the usual impersonal scientific talk, where one says, "The apparatus was designed and built, measurements were taken, and the following results were obtained." This lecture, according to custom, is supposed to be a personalized account of one's scientific career. To give such a talk, one must either spend a great deal of effort in avoiding the first person pronouns, or else let the bars down, and say "I and me" wherever it seems natural. I will follow the example of my recent predecessors, whose talks I have read in the past week, and use the first person without further apology. And since an hour's talk about thirty years of work gives an average of only two minutes per year, I'll 
have to skip over lots of things that seemed important to me at the time, to concentrate on a few selected items.

The word "Adventures" in the title of this talk is intended to convey the feeling that most physicists have about their work: To us, the pursuit of science is an adventure, which according to Webster, is an undertaking whose outcome is uncertain. And beyond that, my scientific career, like that of many of my contemporaries in peace and war, has led me into adventures of the more familiar kind--trips to foreign lands in search of cosmic rays, to a previously secret Russian laboratory, to test flights in new aeroplanes, and to uncomfortably close proximity to exploding atomic bombs. Nothing that I read about physicists during my college days would have suggested such a life--I looked forward to the life my professors led; they spent most of their time in one or two small rooms in the basement of the physics building, and came out only to lecture to their class, or to build some apparatus in the machine shop. The man who was largely responsible for changing the working habits of physicists was my long time friend and teacher, Ernest Lawrence, who encouraged his colleagues to leave their small rooms, and work together in the stimulating teams that are now commonplace. But while I recognize that the large team approach is the only way to attack the basic problems in high energy physics, I still react with envy as I walk past the laboratories of my friends in the fields such as nuclear spectroscopy and solid state physics--they still have the great satisfaction that comes from doing and publishing their own work--not as the fourth author in a list of six names.

I will speak only briefly about my early life, because it appears to be typical of those who become experimental physicists. I had the good fortune to be exposed as a boy, to electrical and mechanical apparatus in the laboratory of my father, who was doing physiological research at the U. C. Medical School in San Francisco. He realized that I would probably go into experimental science of some sort, and he arranged for me to work two summersas an apprentice in a scientific instrument maker's machine shop. That was wonderful preparation for a young physicist who was to work in the prewar days, when if you needed some apparatus, you built it yourself, because the three professional machinists in the department shop were all working for the full professors. 
I went to the University of Chicago in the belief that I would probably become a chemist. This was natural in view of the fact that all the popular science books I had read in high school concerned themselves with the lives and great deeds of chemists. It is hard to realize how recently the word physicist has come into common usage. For some years after I received my $\mathrm{Ph}$. D. in physics, I would answer questions from laymen, concerning my work, by saying that I was a chemist--it took too much of an explanation to say what a physicist did.

It took me two and one-half years of college, and seven straight $B^{\prime} s$ in my chemistry courses to convince me that I wasn't cut out to be a chemist. Fortunately, at about the same time, I became fascinated by my physics courses, and discovered the Physics Department Library, and the "original literature". I had never read any chemistry outside of my text books, but I now found myself spending all my spare time reading in the library.

My first love in physics was Optics, and this was natural, because Professor Michelson was a member of the Chicago department, and he had won his Nobel Prize for his very ingenious optical studies. I never saw Michelson, because he died in California, in my junior year, while he was making his final determination of the speed of light. But he played a tremendously important part in my growth as a scientist; he was my first scientific hero. I read every word he published in his long and distinguished career, and I became intimately acquainted with the vast array of optical apparatus he had accumulated in his laboratory rooms. He was unusual for a physicist in that he had almost no close scientific associates or graduate students--he did his work in collaboration with a devoted team of former machinists and optical technicians, who could build anything out of metal and optical glass. I became a close friend of each of these men, and they spent long hours teaching me physics the way Michelson had taught them. From them, I derived the intense interest I have always had in diffraction gratings--the most precise instruments that scientists have to split light into its component colors, or to produce the rainbow-like phenomenon that we call the optical spectrum. In the past few years, diffraction gratings have appeared in the form of costume jewelry--my wife is sitting 
down in the audience, wearing a pair of diffraction grating earrings, which show rainbow-like colors that change with the viewing angle.

Michelson's team spent. about thirty years trying to build a machine which would make more perfect diffraction gratings than were then available. The problem is exceedingly formidable--to make such a grating, one has to scratch about a hundred thousand straight and parallel lines on a piece of optically polished metal. The lines cover an area of perhaps four inches by six inches, and they must be scratched by a diamond point so that they are all equally spaced, to an accuracy of about one millionth of an inch. After Michelson's death, my friends on his team let me share their few triumphs and many disappointments, as diamond points broke in the middle of a grating after several days of successful operation; or as small temperature changes distorted the pitch of the screw that spaced the lines. The experiences I've just related played a very important part in the development of the machines which we now use to make accurate measurements of bubble chamber photographs.

It is not surprising after this introduction to physics, that my first scientific paper, which I published in a Science teacher's journal at the end of my junior year, concerned a diffraction grating. The article described how one could take ordinary household items; just as an electric light, a yardstick, and a phonograph record, and measure the wavelength of light. The record, with its parallel grooves, acted as a very coarse diffraction grating. And many years later, Professor Jenkins and I published a paper which showed how the resolving power of a grating could be increased several fold, by "multiple diffraction" - ousing the same ruled surface several times in succession.

I'll skip ahead to the war years, to point out an unexpected bonus I derived from my early interest in gratings. In 1941, when I was watching a plane being tracked by a fire-control radar set, it occurred to me that if one could tell the position of a plane well enough to shoot it down, one should also be able to use the same positional information to guide it down to a safe landing. This was the origin of Ground Controlled Approach, or G. C. A. I got together with a group at the MIT Radar laboratory, where I was working at the time, and we built the auxiliary equipment to convert the fire control 
information into landing instructional form. We made arrangements to borrow the fire control radar set for a week, when it was between evaluation tests at two Army bases, and we set up an ambitious series of test landings at a Naval Air Station in Virginia. The tests were a dismal failure--the radar set followed the plane perfectly as long as it was five degrees above the horizon, but whenever it got below that elevation angle, the radar dish couldn't make up its mind whether to look directly at the plane in the sky, or to look at its reflection in the smooth ground--a few degrees below the horizon. That behavior hadn't been noticed ir the field tests, because an antiaircraft gunner isn't interested in a plane at such a low angle. But for blind landing purposes,--well, you can imagine our consternation.

We had previously made a lot of simulated radar landings, using an optical sight to obtain the elevation of the plane under good weather conditions, and we were convinced that the GCA principle was basically sound, if the antenna difficulty could be solved. The solution was obvious; we had to cut down the field of view of the radar antenna, so when it was looking at the plane, it wouldn't be distracted, out of the corner of its eye, so to speak, by the reflection of the plane in the ground. This meant that the antenna would have to be about twenty feet long in the vertical direction, and completely impractical within the state of the art, as it then existed.

To get around this impasse, I designed a new kind of antenna sys tem, which is now known to radio engineers as an electro-mechanically phased, steerable linear array. I knew nothing about antenna theory--I don't mean almost nothing, I mean nothing, but because I could think of a long line of little antennas as a diffraction grating, I could think creatively in an otherwise unfamiliar field. Until that time, every microwave radar antenna had consisted of a single radiating element, or dipole, as we call it, together with a reflecting dish behind it. We were soon building what I will always consider to be diffraction grating antennas, with two or three hundred equally spaced little radiating elements in a line, just like the lines on one of Michelson's gratings.

So far, the word nuclear hasn't appeared in this talk, except in the title, so I must get back on the tracks. As an undergraduate research project, my advisor suggested that I build one of the new fangled Geiger-Muller 
counters, that he had recently read about in the German literature. He assigned me a room of my own on the first floor of the famous Ryerson Laboratory, which I soon learned had been Millikan's laboratory when he had made his historic measurement of the charge on the electron, using the oil drop technique. Of course, I had to build the metallic parts of the counters in the student shop, and then seal them into glass envelopes myself, and evacuate them on a vacuum system I had put together, while learning the art of glass blowing. The most difficult part was the amplifier, because the laboratory didn't own a cathode ray oscilloscope, a signal generator or a vacuum tube voltmeter. For the first two months, when things didn't work, I had no way of telling whether the trouble was in the counter or in the amplifier. But finally, after making every kind of mistake you can imagine, and some that I'm sure my friends who are electronic experts would absolutely refuse to believe could be made, the counter did work. No one in the department had seen such a device before, and I was invited to demonstrate it, and talk about it at the weekly Physics Department colloquium. Actually, I was only allotted half of the hour, because it wasn't thought proper for a mere undergraduate to take up a full hour of the department's time. This was my first scientific talk, and $I$ can remember rehearsing it several times in one of the basement rooms.

About this time, Professor Arthur Compton took an interest in my work, and I became one of his graduate students. For the past month, I've looked forward to having him in the audience when I gave this talk, and I ar. sure you can appreciate the great sadness I felt when he passed away last week. He was the first real physicist with whom I had any personal contact, and the fact that he was a wonderful gentleman, as well as a great scientist, made my experiences with him doubly rewarding.

Professor Compton had just given up his work in the field of X-rays, and had embarked on an ambitious program of measuring Cosmic Rays all over the world. At the time, the nature of the primary Cosmic Rays wasn't understood; Professor Millikan of Cal Tech thought they were high energy gamma rays, which carry no electrical charge. If they were charged particles, like electrons or protons, they should be deflected by the earth's magnetic field, and so they should be more intense near the magnetic poles 


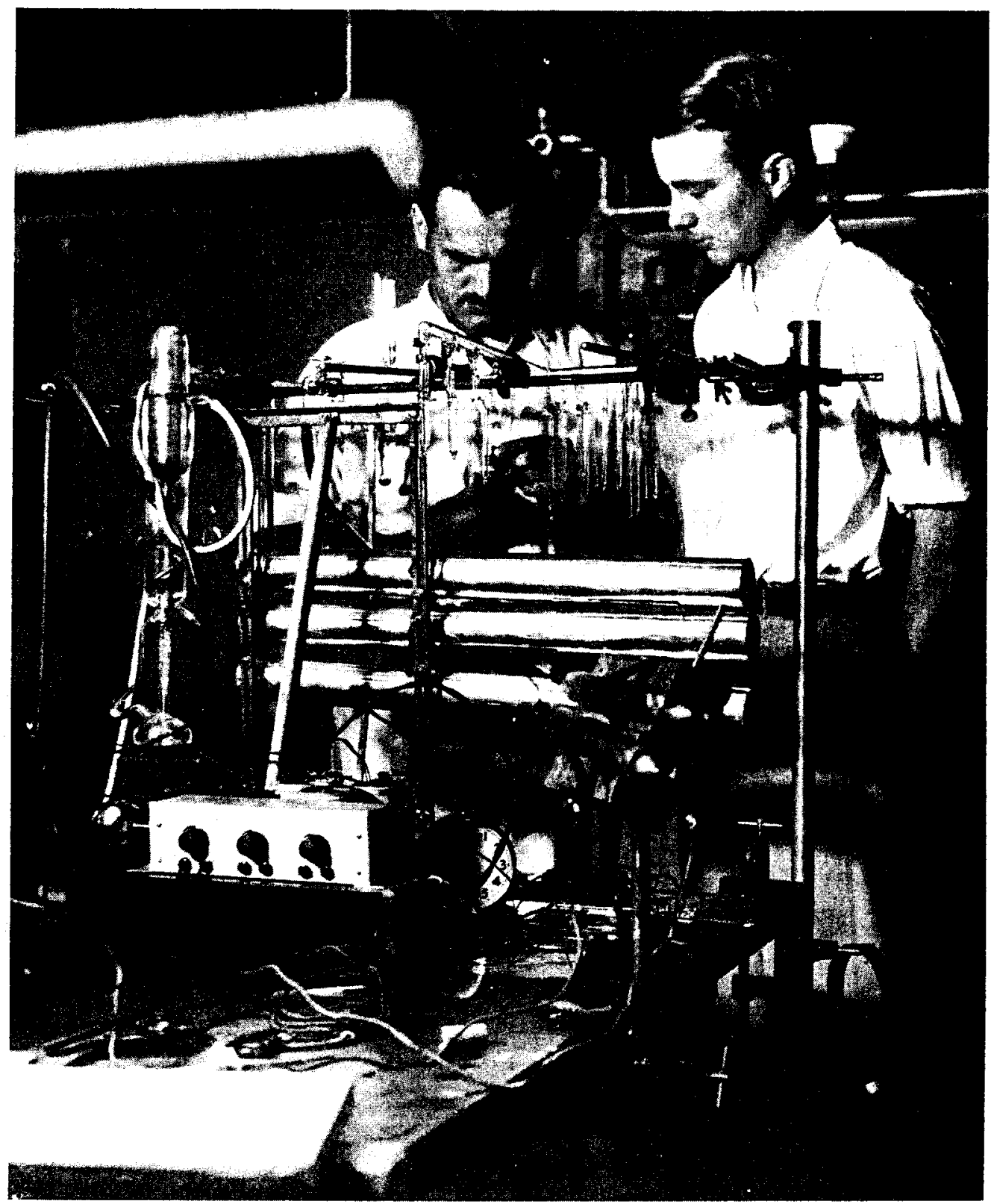

$\mathrm{ZN}-3273$

Fig. 1. Arthur Compton and LWA with Geiger counters, Chicago, 1933. 
than at the equator. Millikan had made measurements from Texas to Northern Canada, and having found no difference in Cosmic Ray intensity, had concluded that the rays were electrically neutral.

A Dutch physicist named Clay had reported that the rays were somewhat less intense near the equator, but because of the great prestige of Millikan, little attention had been paid to Clay's work. But Arthur Compton spent a year travelling all over the world and measuring cosmic rays and confirmed Clay's results--the rays really were charged. But were they positively or negatively charged?

When I was a first year graduate student, Professor Vallarta of MIT gave a talk at Chicago in which he showed how one could tell the sign of the electric charge of the cosmic rays, by using an arrangement of Geiger counters. His proposal was to take a pair of counters that would only be sensitive to rays from a particular angle above the horizon. One would measure the cosmic ray intensity at, for example, $45^{\circ}$ elevation angle, first over the Western horizon, and then over the Eastern horizon. I can't go into the details of the theory, but it obviously depends on the fact that particles with opposite charge are deflected by the earth's magnetic field in opposite directions. If more cosmic rays came from the West, they were positively charged, and vice versa.

Several physicists had looked for the effect, and not found it. Vallarta pointed out with great excitement that they had all done their looking in temperate latitudes, where the magnetic field of the earth had no measurable effect on the rays. He predicted that in his native Mexico City, there would be a large effect.

Arthur Compton realized at once that he had no apparatus that was directionally sensitive, so he asked me if I would like to take my Geiger counters to Mexico City. He said that Dr. Tom Johnson, a well-known cosmic ray physicist from Swarthmore had heard Vallarta's talk and planned to have a look for himself. Vallarta said he would take leave from MIT, and be our host in Mexico City. I worked feverishly to get my apparatus in shape--it had to be converted to battery operation, because the Mexican A. C. voltage was notoriously variable, and stabilized power supplies hadn't been invented yet. Professor Compton obtained a grant from the Carnegie 
Foundation, which came just short of paying my round trip railroad fare to Mexico City. (The modest $\$ 50,000$ research grant had also not been invented!)

Dr. Johnson and I arrived in Mexico City on the same day, and set our apparatus up on the roof of a small hotel. We started measuring cosmic ray intensities a few days later, and within a few hours of each other, had found the so-called East-West effect. We both concluded that the rays were positively charged. We published our data independently in the same issue of the Physical Review, and it was with pride that I saw my first serious paper signed "Alvarez and Compton".

The Century of Progress Exposition opened in Chicago in 1933, and the theme was scientific progress. The previous Chicago World's Fair had been held 40 years earlier, so the new one was opened with light from the star Arcturus, which had been travelling through space for 40 years. The General Motors Corporation was to open its exhibition building a few days before the official opening of the fair, and two weeks before that, Professor Compton had a call from them asking if he could supply them with a cosmic ray signal to turn on their Chevrolet assembly line exhibit. (They had been told that cosmic rays might have been travelling through space for several billions of years). He referred them to me, and so one of my friends and I put together a chrome plated Geiger counter telescope system in the short time available. It was my first experience with what one would now call industrial consulting and I was bowled over when they sent us a very generous check a week after the unit had done its job.

The exposition directors remembered that small county fairs usually featured a balloon flight, and since this was to be the biggest fair, it should have the greatest balloon flight. They asked the famous Professor Piccard to stage a flight for them, but he wasn't available. The Navy supplied their world champion balloonist, Lt. Commander Settle, to be the pilot, and Professor Compton was overjoyed at the opportunity to put some cosmic ray apparatus in the gondola. I spent a good deal of time building apparatus, installing it in the gondola, and testing it for reliability. In the process I became well acquainted with Commander Settle, and he asked if I would like to be the scientific observer on the flight. I naturally jumped 


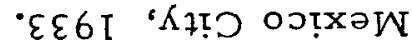

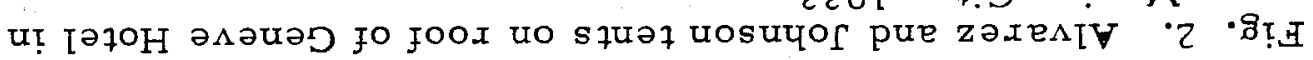

$\nabla L Z \varepsilon-N Z$

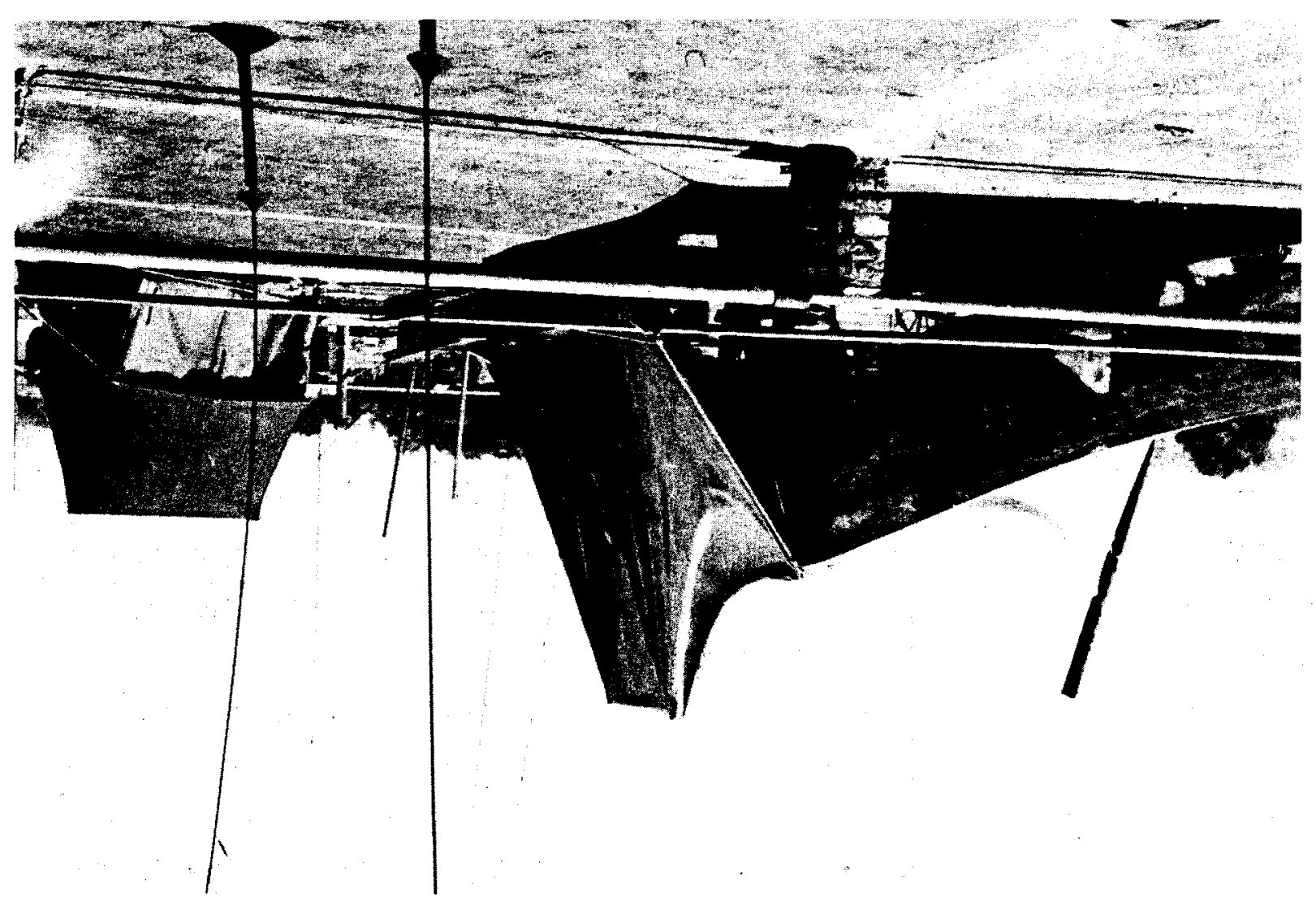




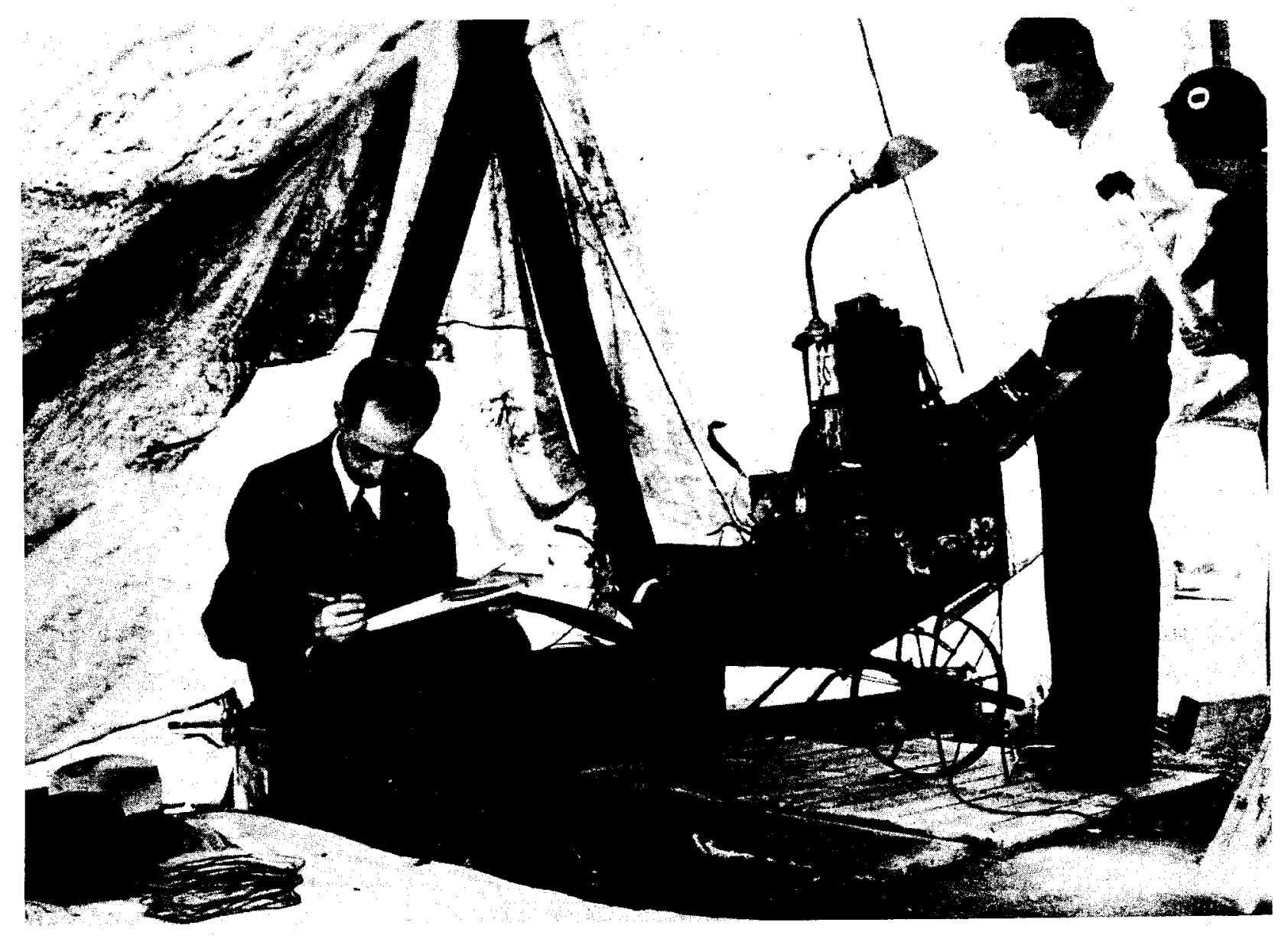

$\mathrm{ZN}-3275$

Fig. 3. My cosmic ray telescope, mounted on wheelbarrow, to permit East-West rotation. Prof. Vallarta at left; Mrs. T. H. Johnson at right. 
at the opportunity, and for several weeks I spent my time working with Tex Settle on the plans. I was greatly disappointed when the management decided to send him up by himself, with no observer aboard. I missed two real adventures by their action, because as part of my learning emergency procedures, I was scheduled to make a practice parachute jump from a Navy plane. The jumping session was of course cancelled when I was no longer to be the observer. As a final anticlimax, the balloon took off a week later, from Soldier Field, with a crowd of 100,000 watching, rose to an altitude of 2000 feet, and then settled slowly into a freight yard a mile away, with all its hydrogen streaming out of the valve at the top of the bag, which had accidentally stuck open.

I spent the next two years working very hard at two experiments, which were useful in that I learned a lot from them, and used them as thesis subjects for my master's and doctor's degrees, but they aren't worth mentioning in any other sense. Arthur Compton could have suggested more prof itable experiments for me to tackle, but he encouraged me to think up my own problems.

I received my Doctor's degree in 1936, in the depths of the Depression. Most of the recent Chicago Ph. D.'s had taken jobs as technicians in the oil prospecting crews which were roaming over the Texas plains--there were no full page ads in the New York Timess offering jobs at $\$ 12,000$ per year, for brand new Ph. D. 's in physics. The reason that I'm not wearing cowboy boots now, is only that my sister was Ernest Lawrence's part-time secretary, and because of that, he had looked me up on one of his visits to Chicago. When I received my degrees he offered and I accepted, a research assistantship, at $\$ 1000$ for the year.

The second stage of my scientific life was the four and a half year period I spent in Professor Lawrence's old wooden laboratory on this campus. It was the most stimulating experience in my career. Everyone worked long hours in the wonderful spirit of cooperation that Ernest Lawrence instilled in his co-workers by the example he set, and by the strength of his personality. As I look back through the collected reprints of the prewar Radiation Laboratory, it is hard for me to convince myself that we really did do that much scientific work, because we had none of the luxuries that 


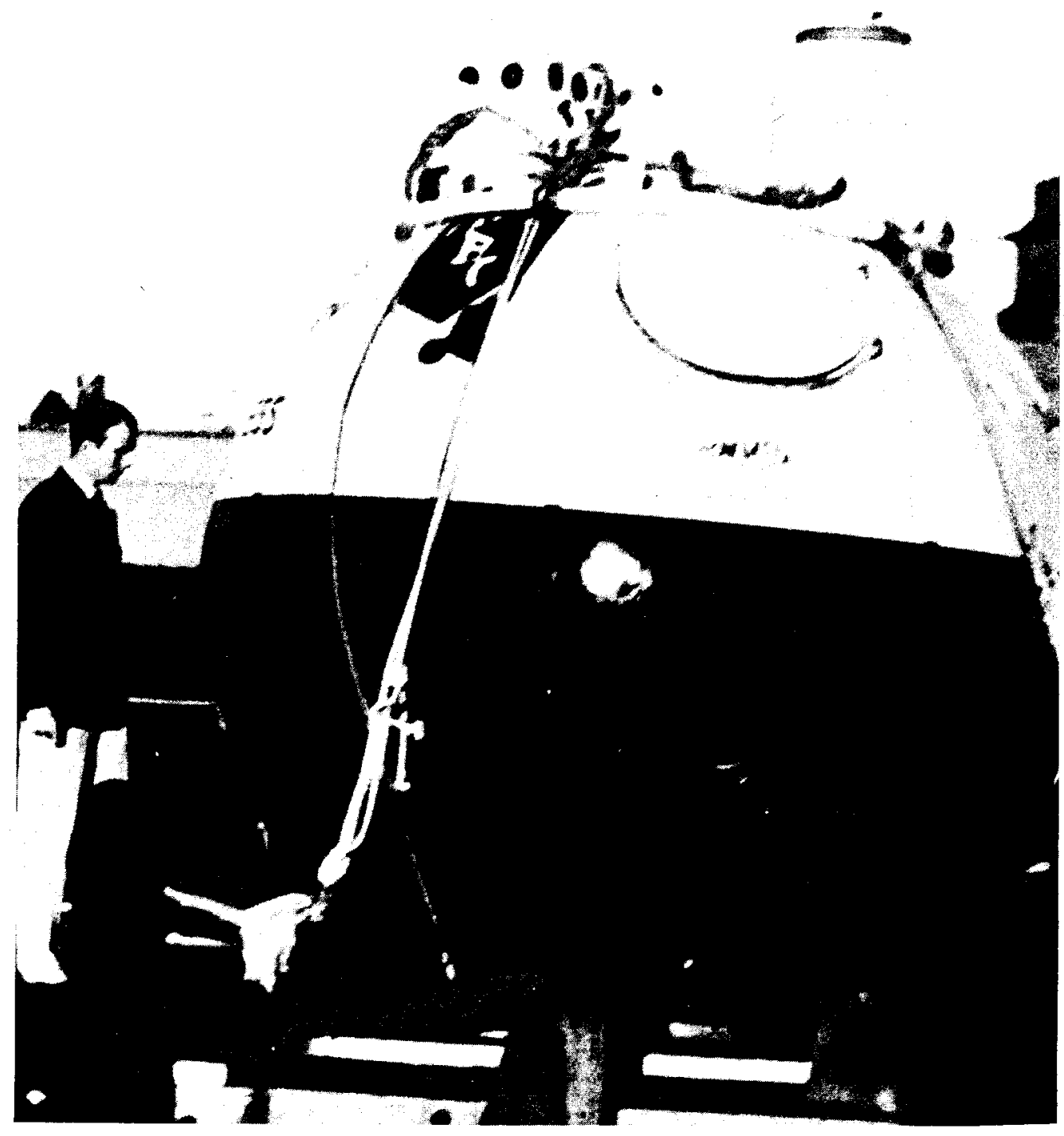

$\mathrm{ZN}-3276$

Fig. 4. Gondola of Settle balloon, Chicago, 1933. 


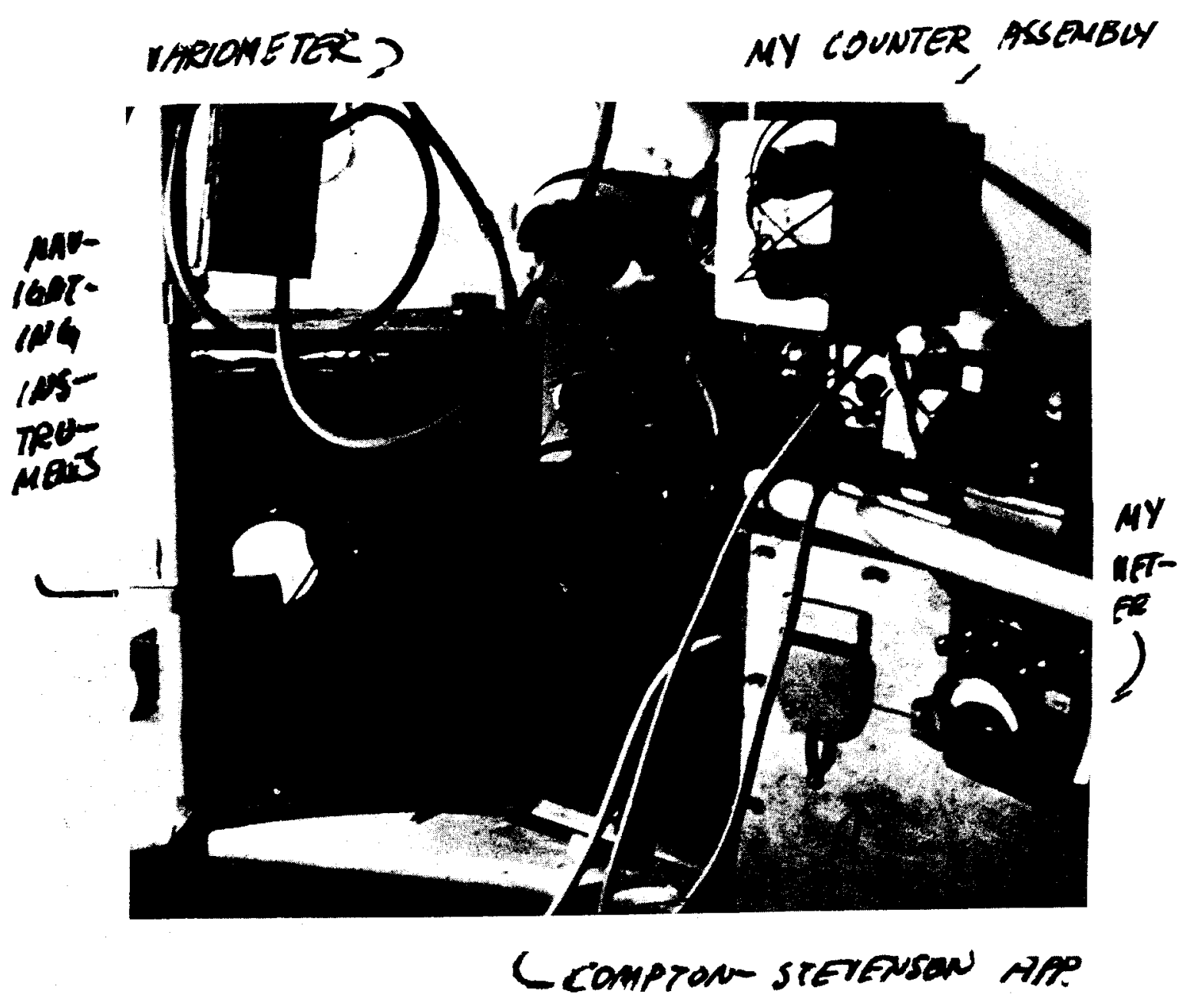

$\mathrm{ZN}-3277$

Fig. 5. Instruments inside Gondola. 
are available to physicists today. Today's cyclotrons and bevatrons are operated and serviced by professional crews; the closest a typical physicist comes to the operation of such a machine today is when he calls the crew chief on the phone, and asks that the beam intensity be doubled. We serviced the cyclotron ourselves, and when the tank was removed from the magnet for repairs, which was frequently, we did the repair work on a 24-hour basis. We took turns operating the cyclotron, while other members of the laboratory staff made measurements on their individual pieces of apparatus. We built our own apparatus, both mechanical and electronic. The reason I find it hard to believe that I turned out a substantial amount of physics in those days is that any time my mind flashes back to that period, I see myself standing at a lathe, hunting for vacuum leaks in the cyclotron system, cleaning out a tar-filled heat exchanger, or wiring up an electronic chassis. I can of course remember in great detail about the measurements I made, and the excitement of discovery that pervaded the laboratory, but the time we had for individual experiments was only a small fraction of the hours in a week.

In 1937, Bill Brobeck joined the laboratory, and as the first trained engineer on the staff, he instituted regularly scheduled maintenance procedures. Over the years, these new practices cut down the amount of emergency surgery that had to be done on the cyclotrons, and permitted the physicists more time for their experiments. When Professor Felix Bloch and I made the first measurement of the magnetic moment of the neutron in 1938 and 1939, we ran on the 37 -inch cyclotron for weeks at a time, with time off only when the machine was used to treat cancer patients, or to prepare radioactive samples for the experiments of other members of the laboratory staff. The recording counters, and the control mechanisms for that experiment were set up close to the cyclotron control desk, so that I could operate the cyclotron myself, and take experimental data at the same time.

Soon after I came to Berkeley, Professor Lawrence raised $\$ 50,000$ to build what is known as the 60-inch cyclotron in the Crocker Laboratory. He told me one day, that he wanted me to design the best magnet to fit into that budget. When I said that I didn't know anything about magnets, he 
merely said, "You'll learn". And I did. This slide shows me holding one of the many pole designs I turned on the lathe, and then tested in the model magnet on the table. Bill Brobeck took the basic magnet design I worked out, and converted it into working drawings. Almost everyone in the laboratory played an important part in the design and assembly of what seemed to us to be a dream machine, where we had money for the first time to build things the way they should be. Dr. Cooksey designed the cyclotron chamber itself, as he had done for the previous two smaller cyclotrons.

The shielding for the 60 -inch cyclotron couldn ${ }^{\circ} t$ be designed until the machine was finished and operating, because no one could predict how penetrating the radiation from such a machine would be. So when the cyclotron first worked, its beam was kept very low, so the internal parts didn't become too radioactive, and so the radiation in the building didn't become too intense. Experiments were then made on the penetrating qualities of the radiation, with the intensity held very low, and from these measurements, the thickness of the shielding material required at full beam level could be calculated. Until the shielding was fabricated, the machine couldn't be used for most of its normal purposes, which required high intensity beams. During this period of enforced idleness as an operating cyclotron, one of my graduate students, Robert Cornog, and I converted the machine into a sensitive mass spectrometer, and discovered Helium 3.

In order for you to understand the significance of this work, I' 11 have to take a few minutes to describe what physicists believed at that time about the important isotopes of Hydrogen and Helium, of mass three. Until 1932. Hydrogen was believed to corsist of a single isotope of atomic mass equal to one, and Helium was believed to consist of a single isotope weighing 4 atomic mass units. Then Harold Urey, acting on a suggestion of our own Professor Birge, found the rate isotope of hydrogen, with mass two, which is now known as deuterium. A year later, Rutherford and his co-workers in Cambridge, England discovered the famous fusion reactions, which are the basic energy producing reactions in hydrogen bombs. The British group found that when two deuterons reacted, the final products of the reactions contained either a helium nucleus of mass three, or a hydrogen nucleus of mass three. These newly discovered nuclei could only be observed when they were moving at high speed, so no one knew what happened after they 


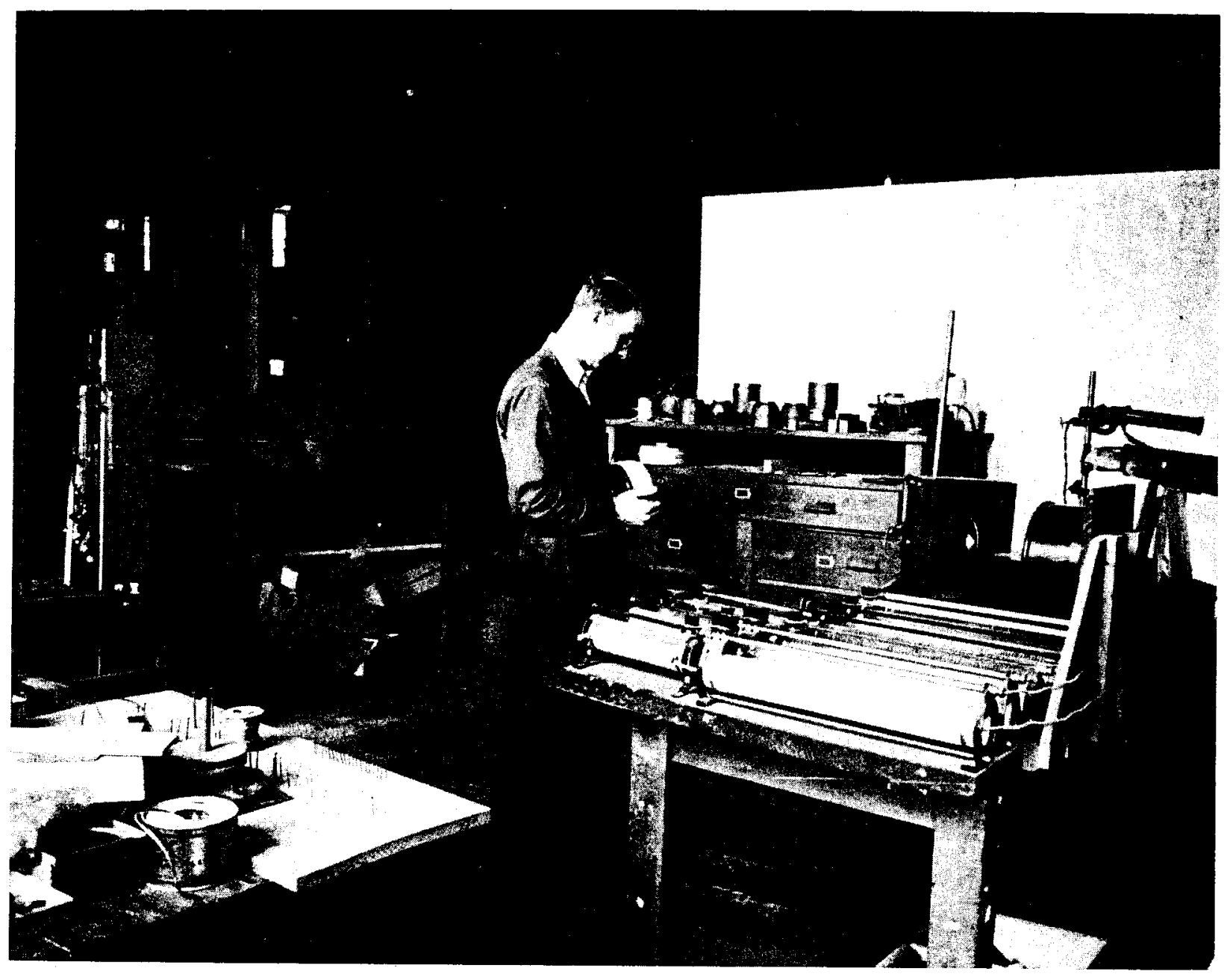

$Z N-3278$

Fig. 6. Testing magnet models, UCRL, 1936. 
slowed down and picked up the one or two electrons they needed to turn themselves into atomic systems. Two independent arguments convinced everyone that Helium three was radioactive, and that Hydrogen three, or tritium as it is now called, was stable. Stable tritium should therefore occur naturally in water, along with ordinary hydrogen and deuterium. As we shall see, the arguments were wrong.

I won't go into the arguments now, because they are fairly technical, and don't add anything to the story. But the best proof that physicists believed them at the time, is that Lord Rutherford's last published paper, just before his death, dealt with a search for stable tritium in a highly concentrated sample of heavy water. He searched the sample fortritium, using the most sensitive mass spectrometer then available, and found none present. Had there been the slightest question in his mind about the possible radioactivity of tritium, he would have put the sample near a Geiger counter, and seen it go wild. Professor Libby found the old concentrated water sample in the Cavendish Laboratory museum in Cambridge after the war, and even then, ten years after Rutherford" $s$ death, it made a counter rattle with its radioactivity.

One evening, I calculated, from the known rate of production of Tritium and Helium 3, that we could make enough of both kinds of atoms in an hour's bombardment at the 37 -inch cyclotron, so that we could subsequently detect them as accelerated ions in the 60-inch cyclotron. In particular, I was excited at the prospect of measuring the radioactive half life of Helium three. The experiment would consist of three parts. We would bombard deuterium gas with high energy deuterons from the 37 -inch cyclotron. The gas would then have a very small admixture of tritium atoms and $\mathrm{He}^{3}$ atoms. We, and here I mean Bob Cornog and I, because by now I had enlisted his aid in doing the experiment - we would then take the bombarded gas and feed it into the ion source of the 60-inch cyclotron. We would lower the magnetic field of the cyclotron to three quarters of its normal value, and then we should be able to detect the accelerated Helium three ions in a counter. Then we would repeat the experiment from day to day, and watch the counting rate of the Helium three ions fall off with time, due to the radioactive decay of the Helium three nuclei. 
The only unknown in the technique involved the possible background of accelerated ions of ordinary varieties, at the reduced magnetic field, where the Helium three ions should appear. No one had looked with a counter at the directly accelerated beam, between the main resonance peaks: - - it was only known that the ion current there was less than a small fraction of a microampere. But a microampere is still more than a million million ions per second. So we had to check the background ourselves.

The next slide shows the experimental set-up. This big box is the amplifier which takes the tiny electrical signals from the counter, and makes them strong enough to deflect the beam of this cathode ray oscilloscope.

The counter is down here, in this picture, but during the experiment, it was placed here, in front of the cyclotron's beam window. The cyclotron was turned on, and we made sure it was running well, by acceler ating ordinary Helium ions of mass four. Then Bob Cornog lowered the magnetic field, while I watched the cathode ray tube. The counter quickly recovered from being blasted by more than a million million ions per second, and the counting rate dropped literally to zero. It stayed there as we passed. through the interesting region at $3 / 4$ field strength, and nothing happened until the field dropped to $1 / 2$ its normal value, where we saw the expected accelerated protons. We were naturally very happy at this complete lack of background, and we talked back and forth on the intercom about how soon we could get our bombardment at the 37 -inch cyclotron, and then start looking for Helium three with the apparatus we had just checked out. After making two or three more slow searches through the Helium three region, we went back up to full field, to make sure that the cyclotron was still working. As soon as I saw the blast of ordinary Helium ions, I said "O.K. Bob, cut the field." He pushed the "off" button on the magnet, and two fortunate things occurred. First, he didn't turn off the main oscillator, which is the standard thing to do under such circumstances, and secondly, I kept my eye on the cathoderay scope, when there really wasn't any reason to do so. As the field dropped rapidly, I noticed a burst of accelerated ions hit the counter just as he called out that the field was at $3 / 4$ normal. We tried the experiment a number of times, and always found Helium three counts when the magnetic field was changing rapidly, but never when it was steady at 


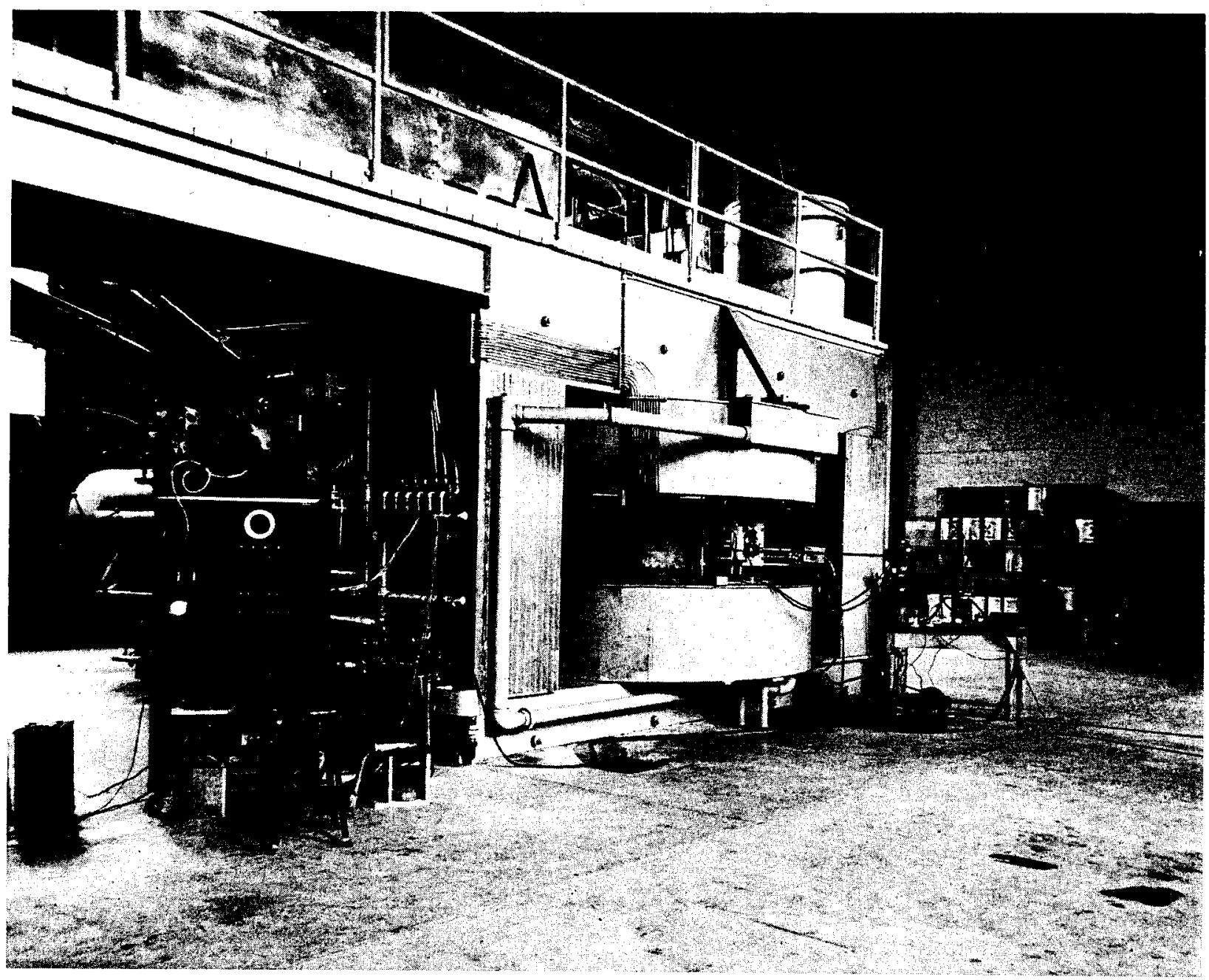

$\mathrm{ZN}-3279$

Fig. 7. Apparatus used in the discovery that $\mathrm{He}^{3}$ was a stable constituent of ordinary Helium. UCRL, 1939. 
the same value. It was soon obvious that eddy currents in the magnet core were restoring the focussing properties of the cyclotron: and that Helium three was a stable constituent of ordinary Helium.

In a few days, we had shimmed the magnetic field so that Helium three ions could be seen with a steady magnetic field, and we found the surprising fact that there is ten times as much Helium three in atmospheric helium as in gas well helium.

Since we had shown that the properties of the isotopes of mass three had been misguessed, we set about immediately to look for the radioactivity of tritium, which we made by bombardment in the 37 -inch cyclotron. This was a perfectly straightforward job, and the details are of no interest here. As a detecting device, we used one of Emilio Segre's ionization chambers, and his electrometer tube set-up. In this connection, it is interesting to recall how much interchange there was in those days of apparatus built with loving care by the individual staff members, and to recall further, how much help each of us received from our colleagues. When I discovered a new kind of radioactivity, known as electron capture, my detecting device was a quartz-fiber electroscope, which had been completely hand-built by Ed McMillan, for his own use. The first chemical separations of radioactive materials for that experiment were done for me by Glenn Seaborg, and he later taught me how to do them myself. Bill Libby prepared the Boron Trifluoride gas that I needed for the first neutron time of flight experiments, and he personally filled my ionization chamber, in his own laboratory。

I have spent most of the time I allotted for talking about this most productive part of my scientific life, on two experiments that didn't take a week of elapsed time. The reason is simply that a physicist gets his greatest satisfaction from finding something that is both unexpected and significant. I believe that the experiments that occupied most of my time in this period were significant, but they were either discoveries of predicted effects, or measurements of important, but obviously measurable, nuclear properties. As examples, I have already mentioned the discovery of $\mathrm{K}$ electron capture, which had been predicted by Yukawa, and the measurement of the neutron moment. I also pioneered some new techniques, such as heavy ion 
acceleration in the cyclotron, and the neutron time of flight method.

Kenneth Pitzer and I measured the scattering of very slow neutrons in orthoand para hydrogen using this technique. Wiens and I made the first $\mathrm{Hg}^{198}$ filled lamp, and showed that its pure line structure made it an ideal standard of length--the Michelson influence again!

I was fortunate in that most of the problems I picked to work on were of some significance to the development of physics at that time. I believe that this was due in large measure to my familiarity with the experimental literature in nuclear physics. I read systematically through all the original papers in the literature, starting from 1920, and made a comprehensive card file of abstracts for my own use. No one could possibly do that now, but the hundreds of hours I put in on this program served me well.

To put things in proper perspective, I would like to mention a major goof I made, because I didn't realize how important a certain observation would be. As soon as fission was discovered, (and Ken Green and I verified it the day it was announced in the daily papers, everyone guessed that neutrons would be emitted at the same time, and these would make the chain reaction possible. My neutron time of flight apparatus seemed an obvious way to find these neutrons, if they existed, because it could yield a flux of pure thermal neutrons; something that no one else in the world had available at that time. I remember going over to the Chemistry storeroom, and signing out for a few pounds of uranium oxide. I put this near my big counter, and looked for the secondary neutrons. When I didn't see any effect in a couple of minutes, I merely said, "Too bad, "and went back to what I was interested in at the time. There is no doubt that had I taken an hour off to move the counter closer to the cyclotron, and to collect some more Uranium, the counts would have been there. I was very surprised to learn later, that Fermi and Szilard at Columbia, and Halban and CurieJoliot in Paris, had spent many months looking for these important neutrons, with exceedingly difficult techniques, and had finally found them. (They had to find their fission neutrons in the large background of fast neutrons which I had eliminated by the "time of flight" technique). This is the kind of skeleton that most physicists probably have in their closets. I know of no other place to publish such a humiliating experience, except at a lecture like this. 


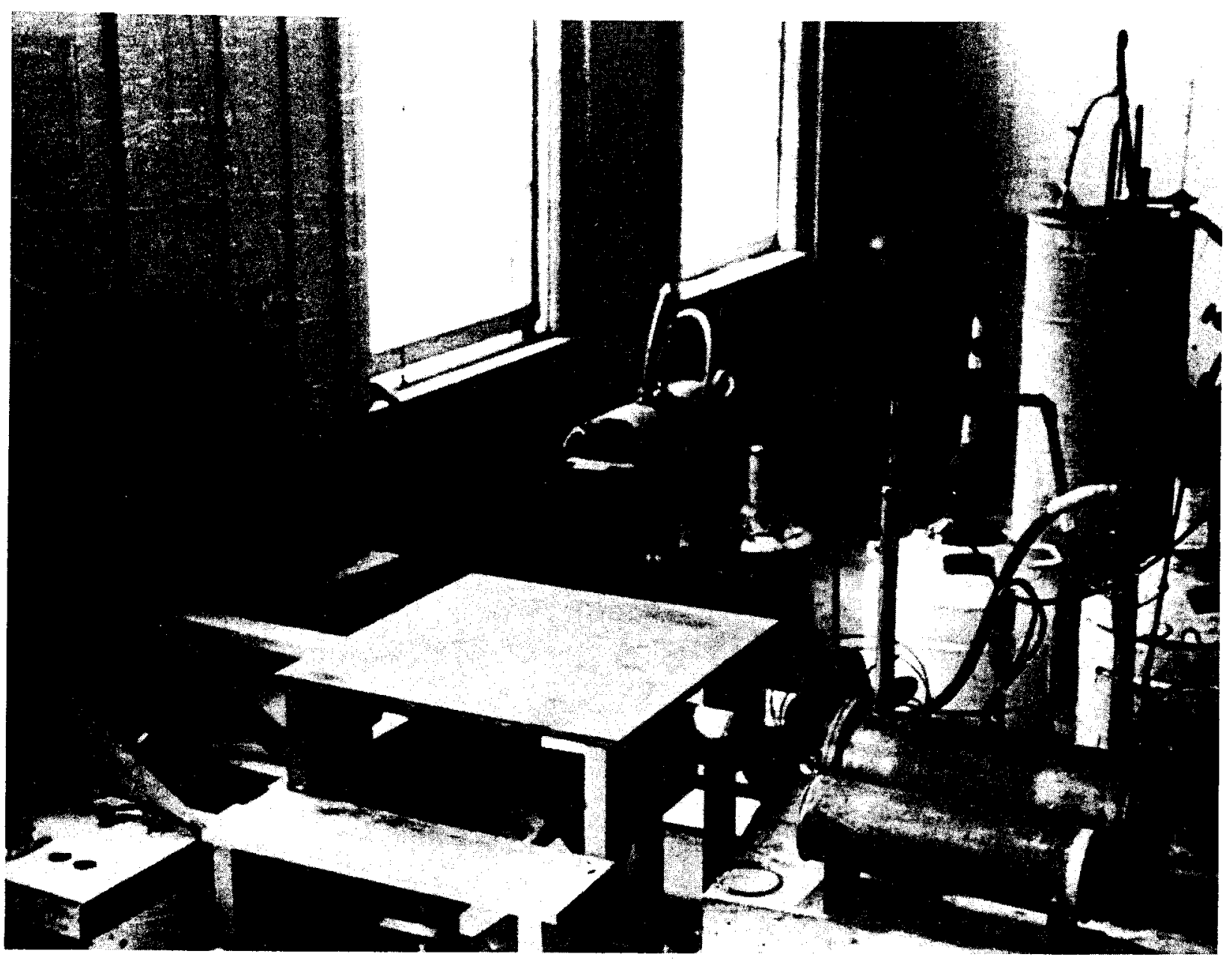

$\mathrm{ZN}-3280$

Fig. 8. First neutron time-of-flight apparatus, with liquid hydrogen apparatus used in "ortho-para" scattering experiments, with Kenneth Pitzer, UCRL, 1940. (Absorber selector wheel at left; $\mathrm{H}_{2}$ gaseous absorber, and dummy chamber at right.) 

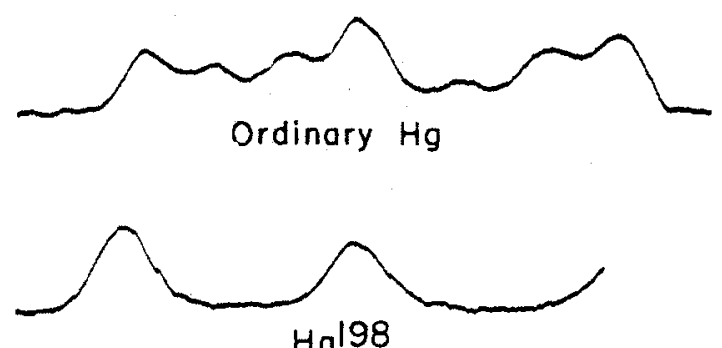

$\mathrm{Hg}^{198}$

Fig. 9. First spectrum ever seen of an artificially created element; Mercury 198 made from Gold - - a reversal of the "alchemists dream". With Jacob Weins, UCRL, 1940. 
The third phase of my career spanned the five year period from 1940 to 1945, and during that time, I scarcely had a thought about nuclear physics. Ernest Lawrence came back to the Laboratory in October of 1940 , from a trip to Washington, and he was filled with exciting tales of the great technical achievements of the British Physicists, in Radar and allied fields. A group of prominent American scientists had set up the Office of Scientific Research and Development, to lend technical assistance to the British, and to prepare our scientific defenses in the not unlikely event that we were to find ourselves in the war. A laboratory was being established at MIT, to exploit the possibilities of microwave radar, a field that had just been opened by the invention, in England, of the cavity magnetron. The British had sent a scientific mission to this country, to tell us everything they knew about radar, in the hope that we could push the development of the new techniques they had pioneered, but didn't have the manpower to put to practical use. Ernest Lawrence was the chief recruiter for the MIT Radiation Laboratory, and most of the early members of the laboratory staff were young nuclear physicists of about my age. Ed McMillan and I went to Boston in November 1940, and during the next five years, I was in Berkeley for only one weekend.

It was a good thing that my new work in Radar was so exciting, and its pace was so exhausting, because otherwise I might have felt disappointed at having to leave nuclear physics, where my own work, and that of my students was moving along at such a rapid pace into some most interesting areas. Although it never occurred to me at the time, I now know that I was then in the midst of my most productive years as a working scientist, and the physics I would have done at Berkeley can't ever be recaptured. But in another sense, it was recaptured in a different guise, in the form of useful Radar devices that might otherwise never have existed, and in technical contributions to the Manhattan District Program, both at Chicago and at Los Alamos.

My work in Radar was largely in the area now known as systems design, although I did some work in components design, as I pointed out earlier, in referring to linear antenna arrays. I'll now show a slide of Ground Controlled Approach, or GCA equipment. I did almost all of the 


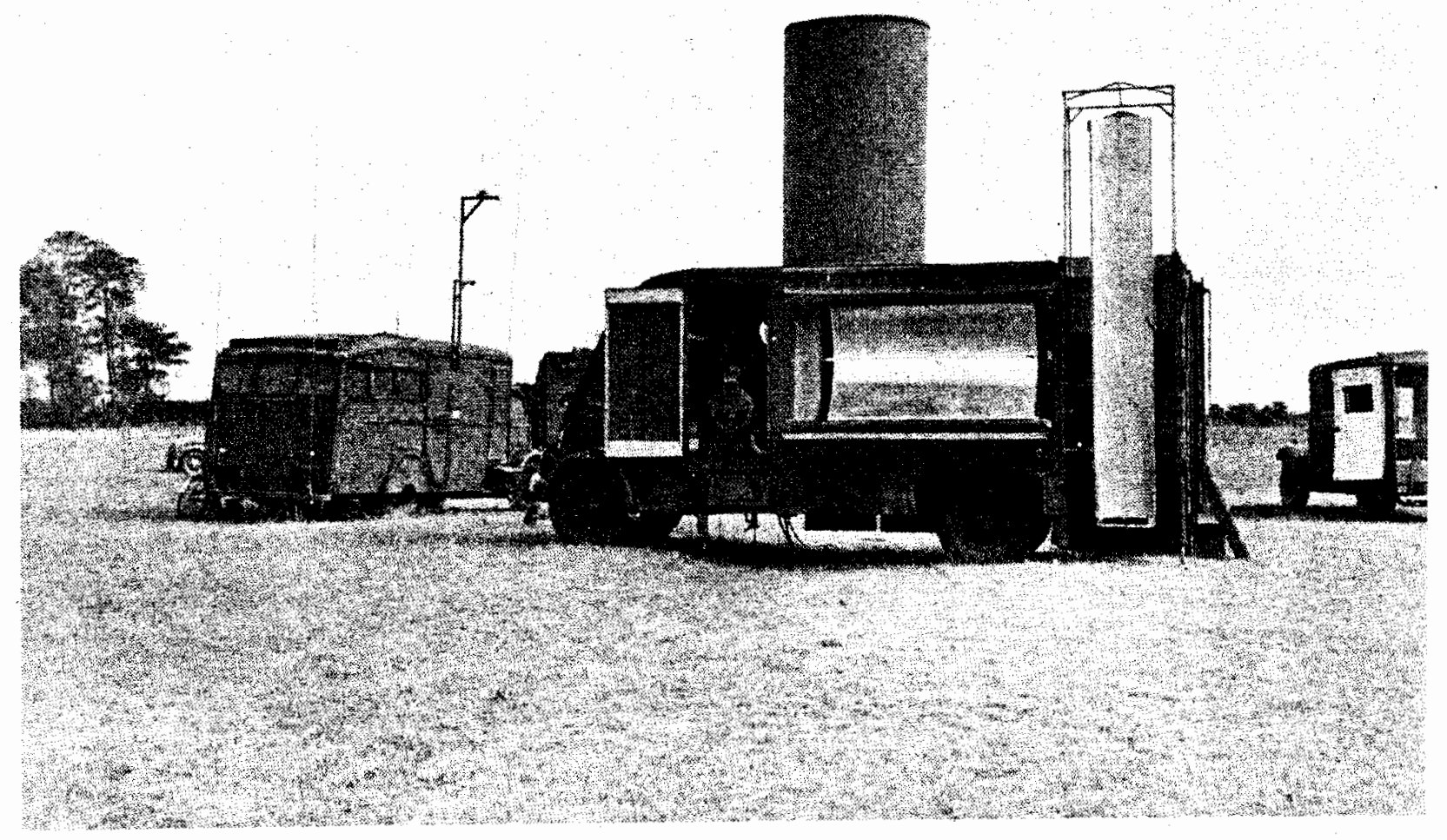

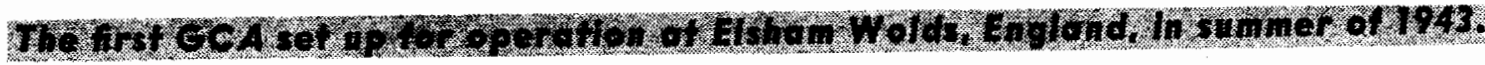

$\mathrm{ZN}-3281$

Fig. 10. 
early "talking down" of the planes. It was interesting to work out the best procedures for conveying information to the pilot in a form that he could use without too much thought. I spent a lot of time in the period learning to fly by instruments, both in a Link Trainer, and in military planes, "under the hood", so that I couldn't see out. I had learned to fly as a graduate student, and that experience, plus the skill I now developed in instrument flying was of great help in the practical business of selling the GCA system to the military pilots. And it also gave me the opportunity to be the first civilian to make blind landings on the system.

The second radar system I designed was the very precise all weather bomb sight known as Eagle. In order to increase the definition of the radar picture of the ground below, the plane was equipped with a 20 foot long wing structure, which housed one of the diffraction grating antennas. The next slides show pictures of B-29's equipped with Eagle radar sets, and radar maps of the same section of Japanese coast line, obtained by ordinary radar and by Eagle. The increased definition, or resolution, as it is called technically, is apparent from the pictures. When I was on Tinian Island at the end of the war, there were two squadrons of Eagle-equipped B-29's in action. They were the first planes to bomb more accurately by radar than by the Norden (Optical) Bomb Sight.

My third radar project was the $\mathrm{MEW}$, or microwave early warning system. It turned out to be an enormously useful and versatile device, both in Europe and in the Pacific area, but credit for its performance must go to those who carried on with its development after I left the Radiation Laboratory, for the Atomic Bomb project. It was just beginning to perform the way I had hoped it would when I left for England with the first GCA set. For a year before that, it was generally thought to be a boondoggle, and it was often referred to as "Alvarez's folly". But its original detractors became its greatest boosters, and the fact that they continued to call it my folly when they loved it dearly, was their way of apologizing for their earlier misjudgment of its usefulness.

I can't leave my radar days without mentioning three names. Lee DuBridge, who is now president of Cal Tech, was director of the MIT lab, and a most valued friend. Alfred Loomis was the head of the Microwave section of the OSRD, and therefore, Dr. DuBridge's immediate superior. 


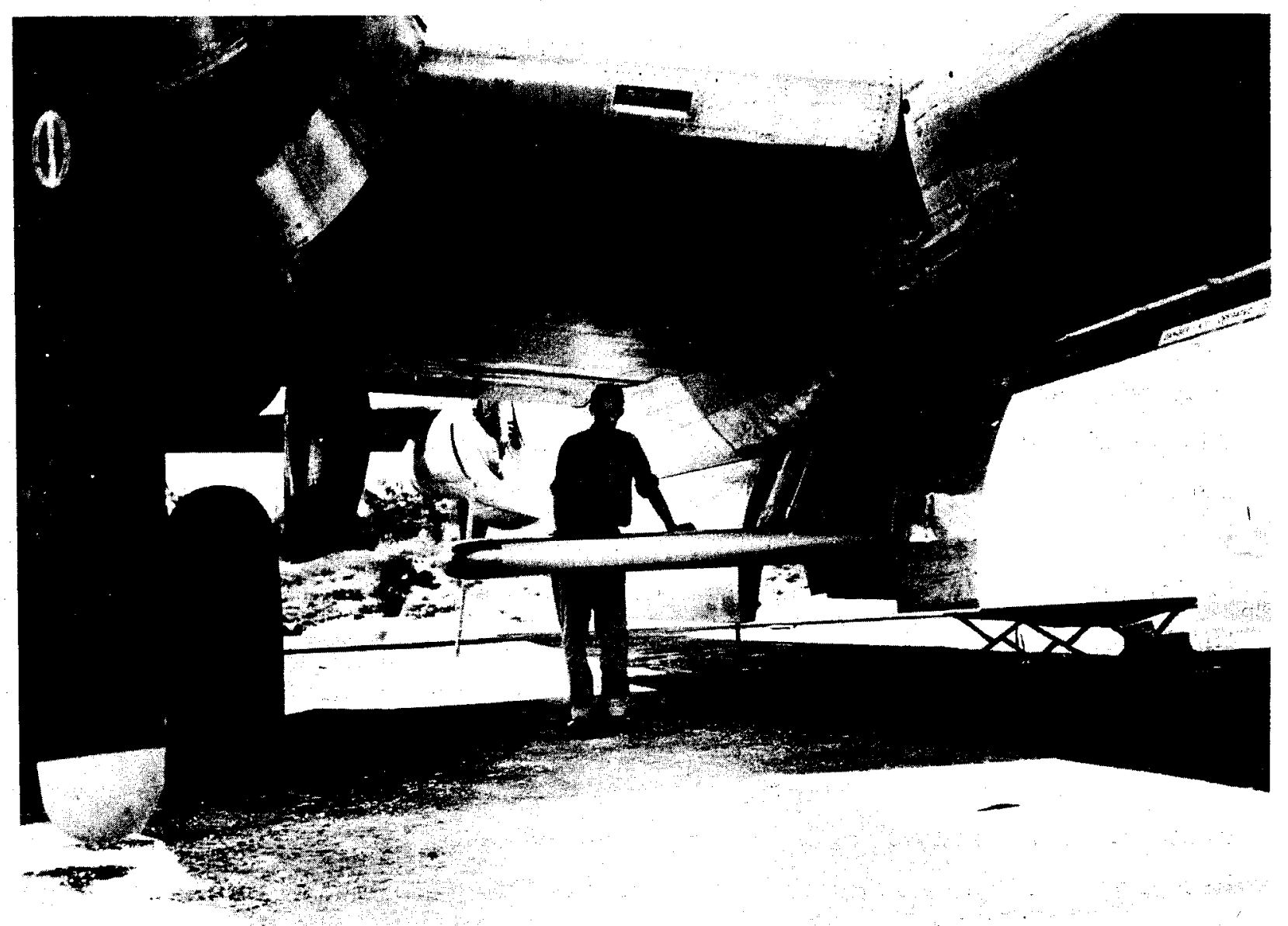

$\mathrm{ZN}-3282$

Fig. 11. Eagle-equipped B-29 on North Field, Tinian Island, Marianas, 1945. 

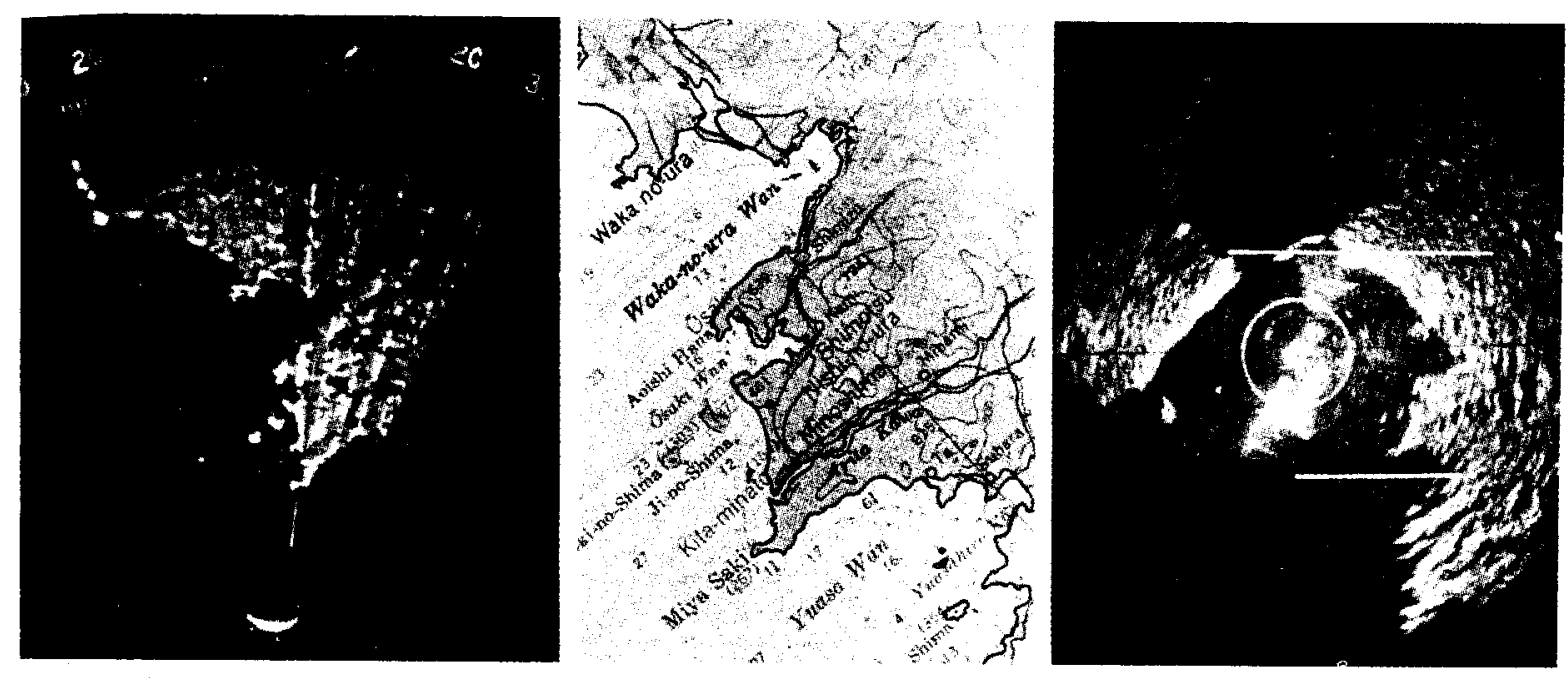

$\mathrm{ZN}-3283$

Fig. 12. Effects of increased resolution on radar mapping. Eagle map on left--standard 3 centimeter radar map on right. 
Dr. Loomis was for twenty years Ernest Lawrence's closest friend and advisor, and he has played an equally important role in my own life. Rowan Gaither was instrumental in getting my three radar sets into production, and in the process, we became very close friends. Rowan later became famous for the Gaither Report, and as President of the Ford Foundation. Until his recent, untimely death, his wise counsel was always available to his large group of devoted friends.

Soon after the Radar laboratory was founded, the atomic bomb program started to move, and it was natural that with my background in nuclear physics, I was asked to join the various atomic laboratories. It was not until early 1943 that I felt I.could leave MIT; by then the projects I had worked on were either in the advanced engineering stage, or in production, so my own contributions were no longer so important. I agreed to join my old friend and colleague, Robert Oppenheimer, at Los Alamos. But first I was scheduled to take the original GCA trucks to England for a real field test.

We set up at an RAF night bomber base in the midlands, and for six weeks, I lived in intimate association with men whose daily job was fighting a war. We landed every type of British and American military plane, from the largest bombers to the hottest fighters, and I talked down pilots of every rank from Sergeant to Air Chief Marshall. As a final test, to see if very tired pilots could use the system, we landed the whole home squadron of 18 Lancaster bombers, after they had flown deep into Germany and back. Actually, it wasn't quite the whole squadron, because two of the planes, flown by my friends, were shot down that night.

While I was in England, I received a telegram from Robert Oppenheimer, saying that Enrico Fermi would like to have me work with him in Chicago. So I spent six months working with the original chain reacting pile, that had just been moved from the squash court at the University of Chicago, out to the new Argonne Laboratory. It was a wonderful experience to work closely with Fermi, and to think about nuclear physics again, but it seemed too far removed from the war. When Robert Oppenheimer put in another call for me, I moved to Los Alamos. But before leaving Chicago, I did one fairly important bit for physics. I discovered the long range alpha particles that accompany the fission reaction in a fraction of one percent of the events. 
My first job at Los Alamos was as a sort of technical aid to George Kistiakowsky, who later became President Eisenhower's science advisor. George was the leading U.S. expert in high explosives, and he had been lifted out of what he considered an important war time job in explosives development, to help with the higher priority Atomic Bomb project. His job was to push the implosion method of setting off bombs, in contrast to the more conventional gun-assembly method. The gun method looked so easy, and the implosion method seemed so extraordinarily difficult, that it was hard to take it seriously. But then Emilio Segre and his co-workers discovered something that made it imperative that the implosion method should work. By this time I had learned just enough about high explosives to be able to do some experiments, but not enough to be sure that an idea I had wouldn't work. By this time, my longtime friend and co-inventer of GCA, Larry Johnston, was working with me in Los Alamos. In one afternoon, he confirmed my guess that a certain critical property of high explosives could be improved by a factor of more than a thousand, and so one of the two or three stumbling blocks in the path of the implosion development was removed, at least in principle. Larry and I then assembled a large team, which made further improvements, and finally the reliable hardware components needed for the bomb were produced.

In April of 1945 my work in this area was finished, so I asked Robert Oppenheimer for a new assignment, which would take me out to the Pacific. He said it was important to devise ways to measure the efficiency of the bombs that were dropped on enemy territory. Normal weapons are tested at proving grounds, and their properties are carefully measured before they are used in combat. But since we couldn' $t$ afford to proof test more than the one bomb at Almagordo, and since the Hiroshima bomb was to be used with no test of any sort, Dr. Oppenheimer suggested that we should make proving ground type measurements over enemy territory. I had three months to decide what measurements should be made, how the equipment was to be designed, and to come up with reliable equipment for use in an operational theater. As had so often happened in the past, Larry Johnston and I joined forces. We decided to measure the blast pressure with a calibrated microphone that could be dropped by parachute from a plane 
which was flying close to the plane that dropped the bomb. The parachuteborne gauge would radio its information back to the instrument equipped plane, where the signals could be recorded in film.

By mid-July, we had several sets of the equipment on the way to Tinian, and were ready to test other sets at Almagordo. The plan was for us to fly in a B-29 directly over ground zero, the site of the bomb: just five minutes before the explosion, and drop the parachute gauges as we passed over. We had radar beacons set out on the ground so that we would know exactly where we were, and radar on the ground would confirm our position. But an hour or so before we were to take off, the plan was cancelled by "higher authority" as potentially too dangerous, and so we watched the explosion from our B-29, at high altitude, about twenty-five miles away. This gave us no opportunity to check the operation of our gauges, and so we had to use them over Japan with no real test.

Two days after the Almagordo explosion, Larry Johnston and I left with the other members of our little group, for Tinian Island, just a mile away from Saipan, in the Mariannas. We checked out our gear, and installed it in several planes of Colonel Tibbet's 509th Group. The next slide shows the gauge assembly with those of us who built it, on Tinian. Just after midnight on the morning of August sixth, we took off immediately after the famous Enola Gay, and flew in formation all the way to the Japanese coast, and then on to Hiroshima, a couple of hundred miles inland. The story of this mission has been told so often that I needn't add any personal observations. From our own small technical point of view, it was a success, because one of our gauges gave a perfect record, and we confirmed the 20 kiloton figure that was made public before we had time to report it to Washington。

And now, since I am one of the few scientists who was close to the bomb development, and who hasn't made a speech or written an article on the decision to drop the bomb on Japan, I'll take just a minute to go on the record. Physicists like to solve simply-defined problems, in contrast to to biologists or psychologists, who deal with enormously complicated systems. When we physicists are confronted with a complicated problem, we usually set up a simplified model of the real system, and then proceed to solve the 


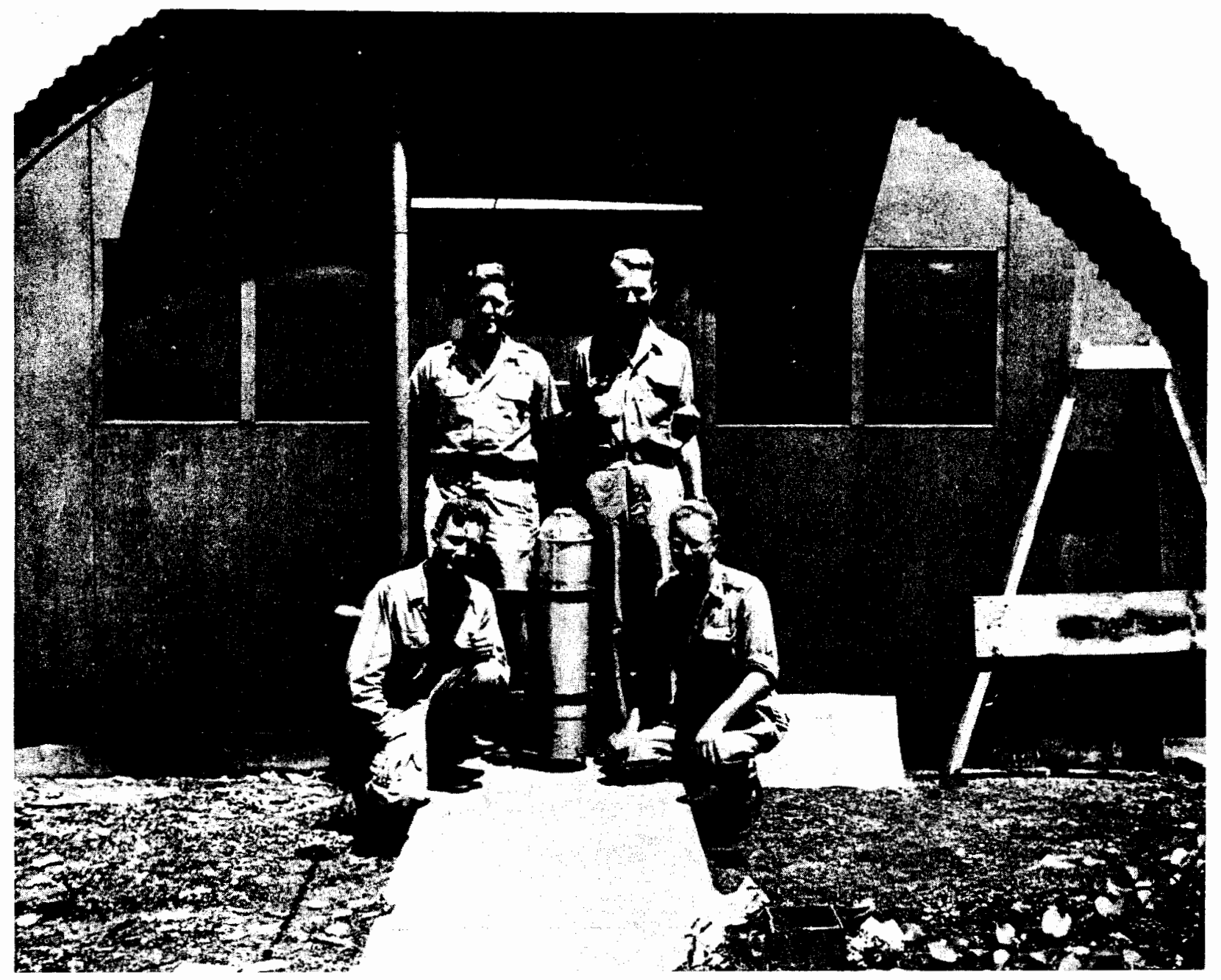

$\mathrm{ZN}-3284$

Fig. 13. Parachute-borne pressure gauge, Tinian, 1945, with "scientific observers" of the 509th Group. From left to right: L. H. Johnston, Harold Agnew, LWA, Bernard Waldman. 
simpler problem. The problem that was asked of the famous committee of Professors Lawrence, Oppenheimer, Compton, Fermi, et al was, "Shall the United States drop atomic bombs on Japan, without previous warning?" The question was not the much simpler one, "Shall the United States engage in a policy of killing Japanese civilians?" That policy was in force at the time, with strong public backing, so with or without the atomic bomb, hundreds of thousands of Japanese would be killed every month until the end of the war. The Committee members believed, and history bears them out, that two bombs dropped in quick succession would end the war. They further believed that a demonstration explosion would not have affected the Japanese will to fight, nor would a single bomb dropped on a city. I believe that this is also borne out by history, because the Japanese didn't talk of surrender until after the Nagasaki bombing. Apparently, they had the papers ready, but they wanted to see if we really had additional bombs available, and were prepared to use them. Each of the four scientists on the committee had been my immediate scientific boss, so I knew them all well. They were all great humanitarians, and I believe they faced up honestly to a difficult question, and gave the proper answer. I think they all felt that they were possessed of the power to press a button that would prevent the needless slaughter of more than a million Japanese and Americans--the civilians and soldiers who would die on both sides before the proposed invasion had defeated the Japanese armies. Had they not pressed the button, I would hesitate to call them humanitarians--in my judgment, they would have had the blood of a million human beings on their hands.

After five years of wartime science and engineering, I returned to Berkeley in 1945, to begin the fourth phase of my career. While at Los Alamos, I had decided that when I returned to Berkeley, I would build a high energy linear electron accelerator, employing the techniques I had learned in my radar work, and using the huge store of surplus radar equipment that would be flooding the peacetime market. My tentative plans were well along, when Ed McMillan told me of the synchrotron, which he had invented the day before. It was so obviously better than what I had in mind, that I immediately dropped all plans for accelerating electrons and decided to do a similar job on protons. General Groves gave the laboratory a blank 
check to rebuild its facilities after the war, so the only problems were technical. I assembled a hard working team of former colleagues, and in just under two years, we had a beam from the 32 million volt proton accelerator. In this period of time, we learned how to solve some new and difficult technical problems in the field of radio frequency engineering, and put together the highest energy Van de Graff generator then attempted. Our 32 million volt protons held the high energy record in their field for over a year, until the 184-inch cyclotron was converted to accelerate protons to 350 million volts. It had then been clear for some time that the linear proton accelerator was a specialized machine, rather than a competitor of the synchrocyclotron. But the linear machine is now the favored preaccelerator for protons that are later accelerated to very high energies in. large machines, such as the Bevatron. And slightly modified in form, it is a very useful tool for the Radiation Laboratory Chemists, where it is known as the Hilac, or Heavy Ion Linear Accelerator.

It took a large team effort to build the linear accelerator in such a short time. I would like to mention Pief Panofsky, Don Gow, Hugh Bradner, Hayden Gordon, Larry Johnston, and Jack Franck, as having played particularly important roles in this program. Larry did his $\mathrm{Ph}$. D. thesis on the scattering of the proton beam from the machine on proton targets. He is now professor of physics at the University of Minnesota. Dr. Panofsky is head of the Stanford Linear Accelerator projects, and Don Gow, Hugh Bradner, and Jack Franck have all been responsible for important phases of the Laboratory's bubble chamber program.

The next slide is one which the Stanford group got a lot of mileage out of when we had a large linear accelerator, and they had a tiny one. Now that they are building one two miles long, I'm open to suggestions for the second-round "needle".

After a couple of years of low-pitched experimental work at the linear accelerator, and the big cyclotron, I joined with Ernest Lawrence in setting up the Livermore Laboratory. After two years of that, I began to think seriously of doing basic physics again in about 1952, just ten years ago. And so I embarked on the fifth phase of my career, and one that has been as stimulating and rewarding as any of the others. All of the previous transitions 

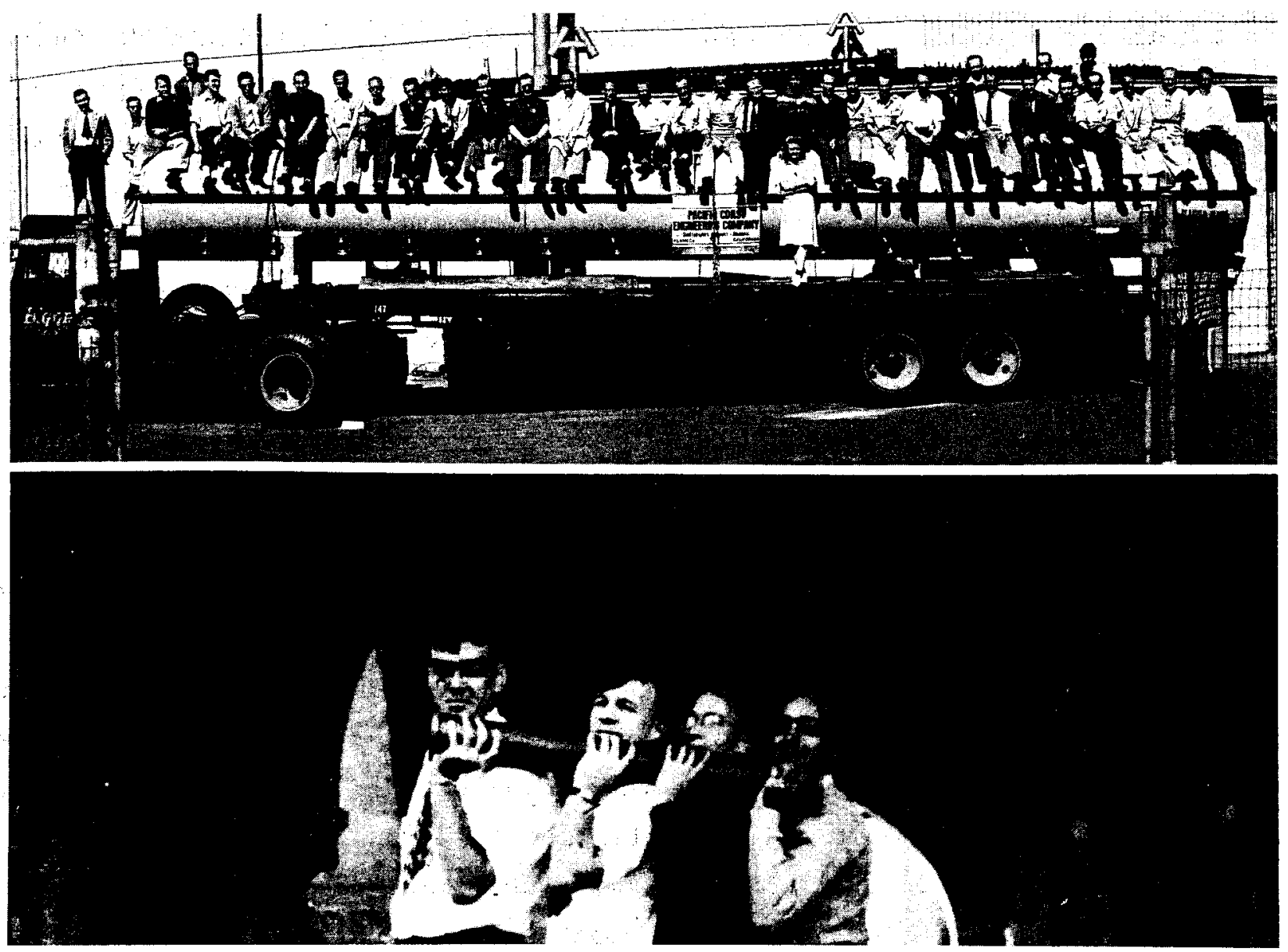

$Z N-3285$

Fig. 14. Berkeley and Stanford linear accelerators, 1946. 
I had made had been smooth and easy, but getting back into real physics, at the age of forty, after a few years away from the front lines, was a real chore. Physicists are like baseball players; they do their best work when they are young, and when they approach forty, they are pretty much washed up as far as their old skills are concerned. Baseball players open bowling alleys, or become managers. Physicists turn into deans or college presidents, or become managers of teams of younger physicists.

So at this stage in my career. I had to face up to the fact that I was a has-been, and the younger physicists wouldn't be impressed by my bibliography or my press clippings. If I was to get back into physics, I would have to learn their language, and make it obvious to them that if they let me work with them in their experiments, I would have something to contribute. When I returned to Berkeley from Livermore, I had no graduate students, and no apparent niche in the rapidly developing field of fundamental particle physics. I was very fortunate in that when Herbert York gave up his professorship in the Physics Department, to assume the directorship at Livermore, he entrusted his two best graduate students to my care. I was very quickly impressed by the versatile talents of these men, Frank Crawford, and Lynn Stevenson, and I made a deal with them. I would hire them as my research assistants for the next two years, as far as the personnel department was concerned, if they would treat me during that time, as if I were their research student. My biggest job was to convince them that I was serious, but after that, they assigned me homework problems, and let me help them with their experiments. It was a thoroughly refreshing experience, even though it was a bit hard on the ego at times. We all had desks together in the same room, along with Don Gow and Hugh Bradner, who were taking the same refresher course. Ernest Lawrence used to joke with me about working in the "bull pen", but he recognized what was going on, and wished that he had the freedom to do the same thing.

Frank and Lynn and I did a couple of experiments together; one on the scattering of gamma rays by protons, and the other on the lifetimes of the $\mathrm{K}$ mesons. The first was difficult and uninteresting, but the second yielded one of the experimental clues that Lee and Yang made use of in their revolutionary theory of parity nonconservation. So after a hiatus of several 
years, I was back in the kind of physics I really wanted to do. I was particularly pleased to find that when I visited the Brookhaven Laboratory about that time, I spent all my time down on the experimental floor at the Cosmotron, talking to the young physicists about the details of their experiments and answering questions about the details of ours. Two years earlier, I would have spent my time in the director's office, reminiscing about the good old days. This was the proof I needed that I had made the grade.

Then I met Don Glaser at a meeting of the Physical Society, and heard about his wonderful invention of the bubble chamber. I went away from our meeting with a resolve to try liquid hydrogen as soon as I got back to Berkeley, and to try to build large chambers to use at the Bevatron. The story of our progress from very small hydrogen chambers to the presently operating 72 -inch chamber is known to so many of you that $I^{\prime} 11$ skip over it rapidly. Several of the members of my group pitched in on the job, and John Wood photographed the first tracks ever seen in a hydrogen bubble chamber. Pete Schwemin and Doug Parmentier immediately started to build a metal-walled hydrogen chamber with glass window, in a two-inch diameter. This was a real breakthrough, as it was the first chamber of any kind to work with rough inside surfaces and gasketed joints. As soon as they finished the two-inch chamber, they started work on a four-inch device, which was the first bubble chamber to be equipped with a magnetic field. At this point, Don Gow took a serious interest in the business, and he has played a leading role in everything that the laboratory has done in hydrogen chambers ever since. He and Dick Blumberg started to design our ten-inch chamber about this time, and I started to dream about the 72 -inch. If it could be built, it would be an ideal tool to use in high energy physics research at the Bevatron. I spoke to Ernest Lawrence about my ideas for the big chamber, and he said he believed it was too large an extrapolation from a 4-inch chamber directly to a 72 -inch chamber. I pointed out that by the time we were ready to commit funds to buy hardware for the big chamber, we would know if the 10-inch chamber worked. If it worked, then there could be no doubt that the 72 -inch would work, because the way we planned to build it, it would have the physical properties of a large number of ten-inch chambers in parallel. 
Professor Lawrence concluded our meeting in a very characteristic way. He said, "I don't believe in a big chamber at this time, but I do believe in you. So if you ask the AEC for the money, I' 11 back you. " After a quick trip to Washington, and the blessing of Commissioners Strauss, Libby, and Von Neumann, the money was made available, and the design was started. Don Gow carried the greatest load, and Paul Hernandez was chief engineer. We had a great deal of help from the staff of the Bureau of Standards Cryogenics Laboratory at Boulder, Colorado. As a result of a wonderful team job, the 72 -inch chamber has been working beautifully for three years. Its smooth operation in the face of many difficulties is due to the herculean efforts of Bob Watt and his bubble chamber crews. I wish that I had time to mention by name all those who have contributed to its success; but that list is very。 very long! However I must mention Frank Solmitz, who almost singlehandedly put us in the forefront of the data analysis business, by writing our first computer programs.

I am naturally much prouder of the important physics that has come from our family of hydrogen bubble chambers than I am of the chambers themselves. If I had to single out one discovery that was made possible by the chambers. I would talk about the catalysis of fusion reactions by mu mesons. I had the pleasure of being a working physicist on the ten-inch bubble chamber experiment at the time this quite unexpected reaction showed up. The fact that it was quite unexpected, and that it took our keenest powers of observation to find it, are the qualities that put it in the adventure class, as far as I am concerned.

The remarks I just made about the mu catalysis have to do with my personal taste in physics. If I were asked to name the most important single bit of physics to emerge from the chambers. I wouldn't choose the mu catalysis reaction, but would concentrate on the "new resonances". But I would be hard pressed to tell you what has been our most significant discovery. I have a suggestion to make if you would like a professional answer to that question. Five of my young colleagues in the bubble chamber physics program are now Associate Professors in the Physics Department. They are Frank Crawford, Don Miller, Art Rosenfeld, Lynn Stevenson and Bob Tripp. I suggest that you keep this date open on your calendars for the years from 1975 to 1980, because I'm sure that, as Faculty Research Lecturer, one or more of them will then give you the answer that I can't give you tonight. 
This report was prepared as an account of Government sponsored work. Neither the United States, nor the Commission, nor any person acting on behalf of the Commission:

A. Makes any warranty or representation, expressed or implied, with respect to the accuracy, completeness, or usefulness of the information contained in this report, or that the use of any information, apparatus, method, or process disclosed in this report may not infringe privately owned rights; or

B. Assumes any liabilities with respect to the use of, or for damages resulting from the use of any information, apparatus, method, or process disclosed in this report.

As used in the above, "person acting on behalf of the Commission" includes any employee or contractor of the Commission, or employee of such contractor, to the extent that such employee or contractor of the Commission, or employee of such contractor prepares, disseminates, or provides access to, any information pursuant to his employment or contract with the Commission, or his employment with such contractor. 